http://jmscr.igmpublication.org/home/ ISSN (e)-2347-176x ISSN (p) 2455-0450

crossref DOI: https://dx.doi.org/10.18535/jmscr/v8i6.07

\title{
Comparison of Two Different Low Doses of Intravenous Dexmedetomidine Infusion in Patients for Abdominal Hysterectomy under Combined Spinal- Epidural Anaesthesia
}

\author{
Authors \\ Dr Sonali Dhawan ${ }^{1}$, Dr Neha Aeron², Dr Bhagirath Bhambhu ${ }^{3 *}$ \\ Department of Anaesthesiology, S.P. Medical College and A.G. Hospitals, Bikaner - 334003 \\ *Correspondence Author \\ Dr Bhagirath Bhambhu
}

Department of Anaesthesiology, S.P. Medical College and A.G. Hospitals, Bikaner (Rajasthan), India

\begin{abstract}
Introduction: Combined Spinal-Epidural Anaesthesia (CSE) combines two techniques thereby providing greater efficacy \& cost effectiveness. Dexmedetomidine is well suited for conscious sedation as patients can be quickly aroused on demand but it has also got many side effects, so its dose is a concern.

Objective: This study compared intraoperative sedation, hemodynamic stability and duration of analgesia between two different low doses of intravenous dexmedetomidine infusion in patients for abdominal hysterectomy.

Methodology: A total of 100 individuals between the age of 30 and 65 years of American Society of Anesthesiologists (ASA) physical status Classes I and II who underwent total abdominal hysterectomies were randomly allocated into two groups, comprising 50 patients in each group. Group -1 received $0.5 \%$ hyperbaric bupivacaine intrathecally and $0.6 \mathrm{mcg} / \mathrm{kg}$ loading dose of dexmedetomidine intravenously over $20 \mathrm{~min}$ followed by $0.3 \mathrm{mcg} / \mathrm{kg} / \mathrm{hr}$ maintenance dose while Group-2 received $0.5 \%$ hyperbaric bupivacaine and $0.4 \mathrm{mcg} / \mathrm{kg}$ loading over $20 \mathrm{~min}$ followed by $0.3 \mathrm{mcg} / \mathrm{kg} / \mathrm{hr}$ maintenance dose intrathecally. Patients were closely monitored for systolic, diastolic and mean blood pressure, pulse rate, SPO2 and Sedation score, every 2 minutes from starting of loading dose of dexmedetomidine till first 20 min followed by every 5 min till the end of surgery. Patients of both Groups were observer for VAS score 24 hours postoperatively.

Results: A dose of $0.6 \mathrm{mcg} / \mathrm{kg}$ dexmedetomidine was associated with more hypotension and sedation as compared to infusion in the dose of $0.4 \mathrm{mcg} / \mathrm{kg} / \mathrm{h}$, with reduction in post-operative analgesic requirements.

Conclusion: Lower dosage of dexmedetomidine $(0.4 \mathrm{ug} / \mathrm{kg})$ can also provide appreciably good analgesia and sedation and is also devoid of significant side effects like bradycardia and vomiting.

Keywords: Spinal-Epidural Anaesthesia, low dose dexmedetomide, sedation, analgesia.
\end{abstract}

\section{Introduction}

The combined spinal-epidural technique (CSE) is defined as the intentional injection of drug into the subarachnoid space with the placement of a catheter into the epidural space as part of the same procedure. Major surgeries below the umbilical level require good relaxation with prolonged and effective postoperative analgesia. In such a scenario combined spinal epidural anesthesia (CSE) has been proposed as an alternative 
technique to standard spinal anesthesia $(\mathrm{SA}){ }^{[1]}$ CSE technique also provides better surgical conditions than with epidural block alone.

Dexmedetomidine is a highly selective $\alpha-2$ adrenergic agonist with an affinity eight to ten times greater than that of clonidine. ${ }^{[2]}$ Various studies have analyzed the dose of dexmedetomidine which causes adequate sedation for patients undergoing surgery. ${ }^{[3]}$

The anaesthetic and the analgesic requirement get reduced to a huge extent with the use of such adjuvants because of their analgesic properties and augmentation of local anaesthetic effects as these adjuvants cause hyperpolarisation of nerve tissues by altering transmembrane potential and ion conductance at locus coeruleus in the brain stem. ${ }^{[4,5]}$ Hence intravenous dexmedetomidine not only provides sedation but also prolongs sensory effect of spinal anaesthesia. So, lesser drug is needed for analgesia in post-operative period.

Although dexmedetomidine has so many advantages but it is not free from side-effects such as hypotension and bradycardia. Lower doses cause less hypotension and less bradycardia, while maintaining their sedative and analgesic effects.

In the background of above facts, a study needs to be conducted to compare the efficacy of two different intravenous doses of dexmedetomidine with combined spinal-epidural anaesthesia in patients undergoing abdominal hysterectomy surgery to evaluate intra-operative sedation, hemodynamic stability, patient comfort and duration of analgesia in post-operative period.

\section{Methodology}

This randomized comparative trial was conducted among the patients posted for hysterectomy at our institute during the period from July 2018 to June 2019 after taking approvals from Institutional Ethics and Research Board (2019/1554/19-032019/09). A valid informed written consent was taken from each of the subjects before enrolling them into the study.

A total of 100 individuals between the age of 30 and 65 years of American Society of
Anesthesiologists (ASA) physical status Classes I and II who underwent total abdominal hysterectomies were randomly allocated into two groups, comprising 50 patients in each group. Group-1 received $0.5 \%$ hyperbaric bupivacaine and $0.6 \mathrm{mcg} / \mathrm{kg}$ loading dose of dexmedetomidine iv over $20 \mathrm{~min}$ followed by $0.3 \mathrm{mcg} / \mathrm{kg} / \mathrm{hr}$ maintenance dose while Group-2 received $0.5 \%$ hyperbaric bupivacaine intrathecally and $0.4 \mathrm{mcg} / \mathrm{kg}$ loading dose of dexmedetomidine intravenously over $20 \mathrm{~min}$ followed by $0.3 \mathrm{mcg} / \mathrm{kg} / \mathrm{hr}$ maintenance dose.

Patients were closely monitored for Systolic, diastolic and mean blood pressure, pulse rate, $\mathrm{SPO}_{2}$ and Sedation score, every 2 minutes from starting of loading dose of dexmedetomidine till first $20 \mathrm{~min}$ followed by every $5 \mathrm{~min}$ till the end of surgery. Patients of both Groups were observered for VAS score 24 hours postoperatively.

A pre-structured pre-tested proforma was used for data collection and Microsoft Office Excel version 2007 was used for data analysis. Continuous variable data was expressed as mean \pm standard deviation and compared statistically using student's t-test. Difference between proportions derived from categorical data was compared statistically with chi square test. P-value of less than 0.05 was considered significant.

\section{Results}

Mean age of patients of both the groups was comparable ( $p$-value $=0.752$ ), as summarized in Table 1. Sedation score was almost comparable in the two groups up to $8 \mathrm{~min}$; after that sedation score was high in group-A till 20 minutes; after that again sedation was comparable in both groups. ( $\mathrm{p}<0.05)$, as elaborated in Table 2 and Figure 1. As shown in Table 3, VAS score was observed less in group-A as compared to group-B. Pain was reported less in group-A as compared to group-B. The difference was statistically significant (P-value <0.05). VAS score was observed till requirement of first top-up. Drug of top-up was same after that in both cases. In group 
A $72 \%$ patients required first top up at 6 hrs while in group B most of the patients required top up at $4 \mathrm{hrs}$ and this difference was statistically significant (P-value <0.05), as shown in Table 4.
Figure 2 depicts that complications such as bradycardia and vomiting were more in group-A as compared to group-B, $\mathrm{p}$ value is highly significant.

Table 1: Age wise distribution of patients

\begin{tabular}{|l|c|c|c|c|}
\hline & \multicolumn{2}{|c|}{ GROUP A } & \multicolumn{2}{c|}{ GROUP B } \\
\hline AGE (in Years) & $\mathrm{N}$ & $\%$ & $\mathrm{~N}$ & $\%$ \\
\hline $30-40$ & 3 & 6 & 15 & 30 \\
\hline $41-50$ & 30 & 60 & 16 & 32 \\
\hline $51-60$ & 17 & 34 & 19 & 38 \\
\hline TOTAL & 50 & 100 & 50 & 100 \\
\hline MEAN \pm SD & $47.6 \pm 6.1$ & \multicolumn{2}{|c|}{$46.9 \pm 9.9$} \\
\hline P-value & \multicolumn{7}{|l}{0.752} \\
\hline
\end{tabular}

Table 2: Sedation Score

\begin{tabular}{|l|c|c|c|c|c|}
\hline \multirow{2}{*}{ Time (minutes) } & \multicolumn{2}{|c|}{ Group A } & \multicolumn{2}{c|}{ Group B } & p-value \\
\cline { 2 - 6 } & Mean & SD & Mean & SD & \\
\hline Base Line & 1 & 0 & 1 & 0 & - \\
\hline 2 & 1 & 0 & 1 & 0 & - \\
\hline 4 & 1 & 0 & 1 & 0 & - \\
\hline 6 & 1.11 & 0.32 & 1.03 & 10.19 & 0.274 \\
\hline 8 & 1.11 & 0.32 & 1.03 & 0.19 & 0.071 \\
\hline 10 & 1.59 & 0.5 & 1.17 & 0.38 & $\mathbf{0 . 0 0 1}$ \\
\hline 12 & 1.74 & 0.47 & 1.28 & 0.45 & $\mathbf{0 . 0 0 0}$ \\
\hline 14 & 1.89 & 0.32 & 1.48 & 0.51 & $\mathbf{0 . 0 0 1}$ \\
\hline 16 & 2.07 & 0.55 & 1.93 & 0.37 & 0.256 \\
\hline 18 & 2.44 & 0.7 & 1.93 & 0.37 & $\mathbf{0 . 0 0 1}$ \\
\hline 20 & 2.7 & 0.47 & 2.48 & 0.51 & 0.096 \\
\hline 25 & 2.78 & 0.42 & 2.83 & 0.38 & 0.646 \\
\hline 30 & 3.26 & 0.66 & 2.93 & 0.53 & 0.094 \\
\hline 35 & 3.26 & 0.66 & 3.03 & 0.42 & 0.13 \\
\hline 40 & 3.19 & 0.62 & 2.93 & 0.26 & $\mathbf{0 . 0 4 8}$ \\
\hline 45 & 3.19 & 0.62 & 3 & 0 & 0.115 \\
\hline 50 & 3.19 & 0.62 & 3 & 0 & 0.115 \\
\hline 55 & 3 & 0.48 & 3 & 0 & 1 \\
\hline 60 & 3 & 0.68 & 3 & 0 & 1 \\
\hline
\end{tabular}

Table 3: VAS Score

\begin{tabular}{|l|c|c|c|c|c|}
\hline \multirow{2}{*}{$\begin{array}{l}\text { Top-up } \\
\text { (hours) }\end{array}$} & \multicolumn{2}{|c|}{ Group-A } & \multicolumn{2}{c|}{ Group-B } & \multirow{2}{*}{ P-value } \\
\cline { 2 - 5 } & Mean & SD & Mean & SD & \\
\hline $2 \mathrm{H}$ & 0.2 & 0.39 & 1.5 & 0.8 & $\mathbf{0 . 0 1}$ \\
\hline $4 \mathrm{H}$ & 1.9 & 1.3 & 3.3 & 1.6 & $\mathbf{0 . 0 0 1}$ \\
\hline $6 \mathrm{H}$ & 3.4 & 1.8 & 1.6 & 1.3 & $\mathbf{0 . 0 0 1}$ \\
\hline
\end{tabular}

Table 4: Postoperative Management (hours) Analgesic Supplementation (Top Up)

\begin{tabular}{|l|c|c|c|c|c|}
\hline \multirow{2}{*}{ Time (hours) } & \multicolumn{2}{|c|}{ Group A } & \multicolumn{2}{c|}{ Group B } & \multirow{2}{*}{ P-value } \\
\cline { 2 - 5 } & YES & $\%$ & YES & $\%$ & \\
\hline 2 & 0 & 0 & 2 & $4 \%$ & 0 \\
\hline 4 & 2 & $4 \%$ & 33 & $66 \%$ & $\mathbf{0 . 0 0 1}$ \\
\hline 6 & 36 & $72 \%$ & 15 & $30 \%$ & $\mathbf{0 . 0 0 1}$ \\
\hline
\end{tabular}




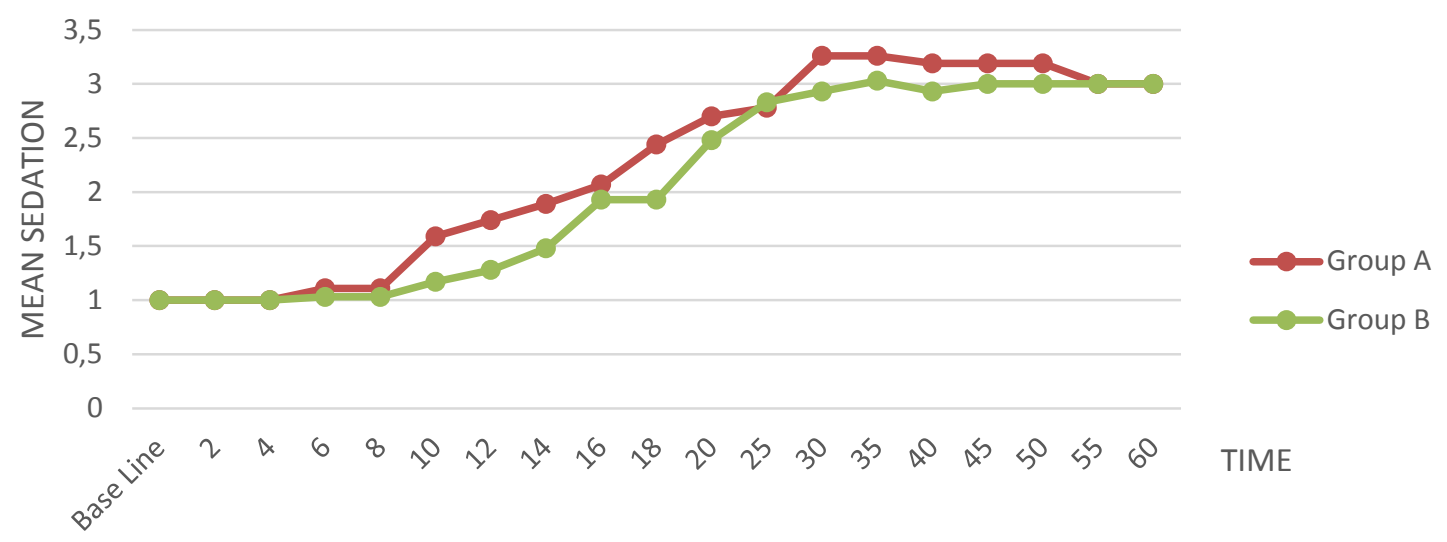

Figure 1: Sedation score

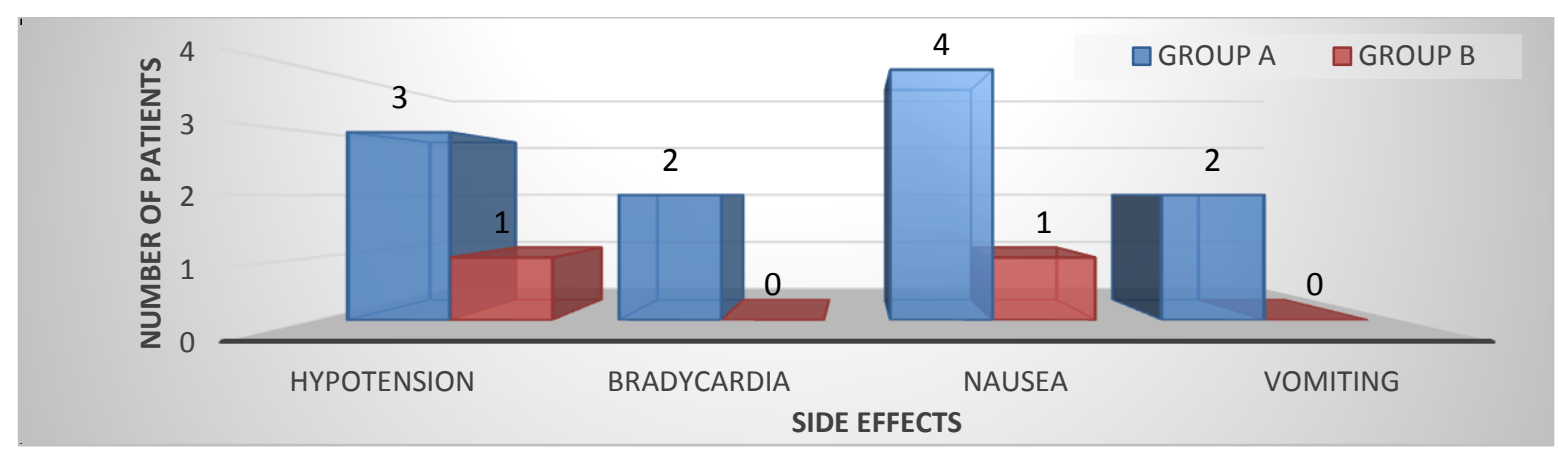

Figure 2: Comparison of side effects in both groups

\section{Discussion}

In present study, patients were divided into 2 groups of 50 each (group A \& group B). The mean age of patients in Group A and Group B were $47.6 \pm 6.1$ years and $46.9 \pm 9.9$ years respectively which were comparable between the groups ( $\mathrm{p}$-value $=0.752$ )

In our study sedation score was comparable in two groups up to $8 \mathrm{~min}$ after that sedation score was high in group-A till 20 minutes after that again sedation was comparable in both groups. Study by Mi Hyeon Lee et $\mathbf{a l}^{[6]}$ found that in the D-1(1.0 $\mu \mathrm{g} / \mathrm{kg}$ ) groups the RSS were significantly higher than in the D-0.5 $(0.5 \mu \mathrm{g} / \mathrm{kg})$ group. Similar to our study, Ebru et $\mathbf{a l}^{[7]}$ evaluated the effects of intravenous dexmedetomidine during spinal anesthesia on hemodynamic parameters and sedation. They took 60 patients and divided them into Group I which received dexmedetomidine infusion and Group II which received saline infusion, there was a statistically significant difference in sedation score with higher in group I.
A study conducted by Park et al ${ }^{[8]}$ (2014) titled "Comparison of two dosing schedules of intravenous dexmedetomidine in elderly patients during spinal anesthesia". In both DMT groups sedation score was significantly more than in control group. Kumkum Gupta et al ${ }^{\text {[9] }}$ in (2015) in their study on patients scheduled for hysterectomy under subarachnoid block, where divided into three groups and were given midazolam $0.05 \mathrm{mg} / \mathrm{kg}$ or dexmedetomidine 0.5 $\mathrm{mcg} / \mathrm{kg}$ or normal saline. In this study, sedation score of dexmedetomidine and midazolam was comparable and the oxygen saturation remained comparable among groups, suggesting that dexmedetomidine produces sleep without respiratory depression. Sebastian, et $\mathbf{a l}^{[10]}$ found sedation scores obtained were higher for dexmedetomidine group than normal saline group. A study by Manne et al ${ }^{[11]}$ showed the effects of low-dose dexmedetomidine infusion on haemodynamicstress response, sedation and postoperative analgesia requirement in patients 
undergoing laparoscopic cholecystectomy observed increased sedation levels with dexmedetomidine.

In our study, VAS score was observed till requirement of first top-up. Duration of spinal analgesia was prolonged in both the groups. The requirement of first top- up was around 6 hours in most of group-A cases as compared to 4 hours in group B cases. This difference was statistically significant ( $p$-value $<0.05$ ). Our results coincided with study done by Mi Hyeon Lee et $\mathbf{a l}^{[6]}$. In their study they found significantly prolonged VAS score in dexmedetomidine group as compared to control group.

In our study, in group A $(0.6 \mathrm{mcg} / \mathrm{kg}) 3$ patients had hypotension, 2 had bradycardia, 4 patients had nausea and 2 patients had vomiting as compared to group-B $(0.4 \mathrm{mcg} / \mathrm{kg})$ where 1 patient had hypotension and 1 had nausea. So the difference is statistically significant for bradycardia and vomiting. All the patients were managed properly. Our results coincide with Mi Hyeon Lee et al ${ }^{[6]}$, Park et al ${ }^{[8]}$ and Kumkum Gupta et al. ${ }^{[9]}$ In concordance with this Khan et $\mathbf{a l}^{[\mathbf{1 2 ]}}$ in their comparative study of $1.0 \mu \mathrm{g} / \mathrm{kg}$ and $0.5 \mu \mathrm{g} / \mathrm{kg}$ doses of dexmedetomidine reported a higher incidence of hypotension and bradycardia with the use of higher dose of the drug. Keshri et $\mathbf{a l}^{[13]}$, also found that the use of lower dose was associated with a lesser incidence of both these side effects. Considering the adequacy of both the low and high doses in blunting the hemodynamic response, the relative safety of lower dose with regard to these adverse effects appears to offer a definite clinical advantage, especially in patients with low cardiac reserve like in geriatric patients. Kapinegowda et al $^{[14]}$ did a study to compare different doses of dexmedetomidine on intrathecal bupivacaine in infra umbilical surgeries. They noticed bradycardia in $3(10.0 \%)$ patients among Group D5 (5 mcg dexmed), 4 (13.3\%) patients in Group D10 (10 mcg dexmed), 10 (33.3\%) patients in Group D15 (15 mcg dexmed), which was statistically significant $(\mathrm{P}=0.044)$. Sebastian et $\mathbf{a l}^{[10]}$ found that dexmedetomidine in a dose of 1 $\mu \mathrm{g} / \mathrm{kg}$ is associated with increased incidence of adverse effects such as bradycardia and hypotension.

\section{Conclusion}

We conclude that even though dexmedetomidine $0.6 \mathrm{ug} / \mathrm{kg}$ bolus gave better analgesia and sedation still results of $0.4 \mathrm{ug} / \mathrm{kg}$ were also appreciable and were devoid of significant side effects like bradycardia and vomiting, which can become fatal specially in cardiovascular compromised patients. So lesser dose of $0.4 \mathrm{ug} / \mathrm{kg}$ bolus infusion can be a useful substitute especially for cardiovascular compromised and elderly patients, but more number of studies is required to establish the above said facts.

\section{Acknowledgements}

Dr.... (.....) for general support in data analysis and statistical analysis and Dr. Shailendra Vashistha (MD IHBT, Senior Demonstrator, Department of Immuno-Haematology \& Transfusion Medicine, SP Medical College, Bikaner) for manuscript preparation and editing.

Source(s) of Support: Nil.

Conflicts of Interest: None.

\section{References}

1. Zaric D, Nydahl PA, Philipson L, Samuelsson L, Heierson A, Axelsson K. The effect of continuous lumbar epidural infusion of ropivacaine $(0.1 \%, 0.2 \%$, and $0.3 \%$ ) and $0.25 \%$ bupivacaine on sensory and motor block in volunteers: A double-blind study. Reg Anesth 1996; 21:14-25.

2. Giovannitti JA, Thoms SM, Crawford JJ.Alpha-2 adrenergic receptor agonists: a review of current clinical applications. Anesth Prog. 2015 Spring;62(1):31-9. doi: 10.2344/0003-3006-62.1.31.

3. Singh DR, Nag K, Nagella AB, Hemanth Kumar VR, Charles AJ.Efficacy of Dexmedetomidine Infusion for Procedural Comfort and Intraoperative Sedation in 
Patients Undergoing Surgeries with Subarachnoid Block: A Randomized Double-blind Clinical Trial.Anesth Essays Res. 2017 Apr-Jun;11(2):294-299.

4. Scheinin M, Pihlavisto M. Molecular pharmacology of alpha 2 adrenoceptor agonists. Baillière's Clin Anaesth 2000; 14:247-60.

5. Correa-Sales C. A hypnotic response to dexmedetomidine, an alpha-2 agonist, is mediated in the locus coeruleus in rats. Anesthesiology 1992;76:948-52.

6. Lee MH, Ko JH, Kim EM, Cheung MH, Choi YR, Choi EM. The effects of intravenous dexmedetomidine on spinal anesthesia: comparision of different dose of dexmedetomidine. Korean $\mathbf{J}$ Anesthesiol. 2014;67(4):252-7.

7. Tarıkçı Kılıç E, Aydın G. Effects of dexmedetomidine infusion during spinal anesthesia on hemodynamics and sedation. Libyan J Med. 2018 Dec;13(1):1436845.

8. Park SH, Shin YD, Yu HJ, Bae JH, Yim $\mathrm{KH}$. Comparison of two dosing schedules of intravenous dexmedetomidine in elderly patients during spinal anesthesia. Korean $\mathbf{J}$ Anesthesiol. 2014 May;66(5):371-6.

9. Gupta K, Rastogi B, Gupta PK, Singh I, Bansal M, Tyagi V. Clinical evaluation of intravenous dexmedetomidine and intravenous midazolam for hysterectomy under subarachnoid blockade with $0.5 \%$ hyperbaric bupivacaine. Ain-Shams J Anaesthesiol 2017;10:279-86

10. Sebastian B, Talikoti AT, Krishnamurthy D. Attenuation of haemodynamic responses to laryngoscopy and endotracheal intubation with intravenous dexmedetomidine: A comparison between two doses. Indian J Anaesth 2017;61:4854.

11. Menne GR, Upadhyay MR, Swadia V. Effects of low dose dexmedetomidine infusion on haemodynamic stress response, sedation and post-operative analgesia requirement in patients undergoing laparoscopic cholecystectomy. Indian J Anaesth. 2014 Nov-Dec;58 (6):726-31.

12. Khan ZP, Ferguson CN, Jones RM. alpha2 and imidazoline receptor agonists. Their pharmacology and therapeutic role. Anaesthesia 1999;54:146-65

13. Keshri RK, Prasad MK, Choudhary AK, Jheetay GS, Singh Y, Kapoor K. Comparative Evaluation of Different Doses of Intravenous Dexmedetomidine on Hemodynamic Response during Laryngoscopy and Endotracheal Intubation in Geriatric Patients Undergoing Spine Surgeries: A Prospective, Double-Blind Study. Anesth Essays Res. 2018 Oct-Dec; 12(4):897-902.

14. Kapinegowda ST, Anandswamy TC, Narayanappa VH, Kumar S, Hatti P. To Compare the effects of different doses of dexmedetomidine on intrathecal bupivacaine in infraumbilical surgeries: A prospective, randomized, double-blind clinical study. Anesth Essays Res 2017; 11:847-53. 